\title{
An overview of percutaneous endoscopic gastrostomy tube placement in the intensive care unit
}

\author{
Margaret Wei ${ }^{1}$, Elliot $\mathbf{H o}^{2}$, Pravachan Hegde ${ }^{2}$ \\ ${ }^{1}$ Department of Internal Medicine, University of California Los Angeles, Los Angeles, CA, USA; ${ }^{2}$ Division of Advanced Interventional Thoracic \\ Endoscopy/Interventional Pulmonology, University of California San Francisco - Fresno, Fresno, CA, USA \\ Contributions: (I) Conception and design: All authors; (II) Administrative support: All authors; (III) Provision of study materials or patients: None; \\ (IV) Collection and assembly of data: None; (V) Data analysis and interpretation: None; (VI) Manuscript writing: All authors; (VII) Final approval of \\ manuscript: All authors. \\ Correspondence to: Pravachan Hegde, MD. Division of Interventional Pulmonology, 155 North Fresno Street, Fresno, CA 93701, USA. \\ Email: PHegde@fresno.ucsf.edu.
}

\begin{abstract}
Critically ill patients are at increased risk for malnutrition as they often have underlying acute and chronic illness, stress related catabolism, decreased appetite, trauma and ongoing inflammation. Malnutrition is recognized as a leading cause of adverse outcomes, higher mortality, and increased hospital costs. Percutaneous endoscopic gastrostomy (PEG) tubes provide a safe and effective route to provide supplemental enteral nutrition to these patients. PEG placement has essentially replaced surgical gastrostomy as the modality of choice for longer term feeding in patients. This is a highly prevalent procedure with 160,000 to 200,000 PEG procedures performed each year in the United States. The purpose of this review is to provide an overview of current knowledge and practice standards with regards to placement of PEG tube in the Intensive Care Unit (ICU). When a patient is considered for a PEG tube, it is important to evaluate the treatment alternatives and identify the best option for each patient. In this review, we provide the advantages and disadvantages of various feeding modalities and devices. We review the indications and contraindications for PEG tube placement as well as the risks of this procedure. We then describe in detail the per-oral pull, per-oral push, and direct percutaneous techniques for PEG tube placement. Additionally, we review the feasibility of having interventional pulmonologists place PEG tubes in the ICU.
\end{abstract}

Keywords: Percutaneous endoscopic gastrostomy (PEG) placement; interventional pulmonology; Intensive Care Unit (ICU)

Submitted Jan 18, 2020. Accepted for publication May 06, 2020.

doi: $10.21037 /$ jtd-19-3728

View this article at: http://dx.doi.org/10.21037/jtd-19-3728

\section{Introduction}

Critically ill patients are at increased risk for malnutrition, particularly given their underlying acute and chronic illness, stress related catabolism, decreased appetite, trauma and ongoing inflammation (1). Malnutrition is recognized as a leading cause of adverse outcomes, higher mortality, and increased hospital costs (2).

Percutaneous endoscopic gastrostomy (PEG) tubes provide a safe and effective method to provide supplemental enteral nutrition to these patients. PEG placement was a technique first described by Gauderer et al. in 1980 (3). PEG placement has essentially replaced surgical gastrostomy as the procedure of choice for a longer term feeding in patients. PEG tubes allow for enteral feeding when oral feeding is not possible or insufficient. This is a highly prevalent procedure with 160,000 to 200,000 PEG procedures occurring each year in the United States.

The purpose of this review is to provide an overview of current knowledge and practice standards with regards to placement of PEG tubes in the Intensive Care Unit (ICU). Additionally, we consider the feasibility of having 
interventional pulmonologists place PEG tubes in the ICU.

\section{Feeding modalities}

When a patient is considered for a PEG tube, it is important to evaluate the treatment alternatives and identify the best option for each individual patient. Below we consider the advantages and disadvantages of various feeding modalities and devices.

\section{Parenteral vs. enteral}

Parenteral as compared to enteral nutrition has been associated with higher costs of care, increased risk of both bacterial and fungal infections, particularly central line associated infections, hyperglycemia, as well as longer ICU length of stays. However, there is no difference in the mortality (4-9).

A recent multicenter randomized control trial found no difference between patients receiving parenteral and enteral feeding with regards to 30-day mortality, but did find an increased risk of hypoglycemia and vomiting with enteral feeding (10).

Also, one recent review found no difference between parenteral and enteral feeding in mortality, ventilator free days, aspiration, or pneumonia. It did however find that enteral nutrition may be associated with lower risk of sepsis as compared to parenteral nutrition (RR 0.59, 95\% CI, $0.37-0.95)(11)$.

\section{PEG vs. nasogastric/nasoduodenal/nasojejunal feeding}

Temporary enteral access can be achieved with nasogastric (NG), oral gastric (OG), nasojejunal (NJ), or oral jejunal (OJ) feeding tube. These options are recommended for short-term use, when feeding is required for a few days or up to one month.

Bedside enteric tube placements are commonly used in the hospital and long term care environments. NG, OG, NJ, OJ can be placed blindly with confirmation of appropriate positioning by auscultation and radiography (12).

A variety of novel systems for navigational guidance during nasogastric tube (NGT) placement are currently being studied. Rivera et al. evaluated the use an electromagnetic tube placement device whereby the tip of a nasogastric feeding tube emitted electromagnetic pulses, which were picked up by sensors on a receiver placed on the epigastric region. He demonstrated successful post-pyloric placement of the NGT with this device and showed that localization with this device correlated with that of plain film radiography (13).

Li et al. studied the feasibility of deploying a flexible uteroscope inside a gastric tube to provide visual guidance for placement of the gastric tube. With this method, there was an increase in rate of successful tube placement and reduced time for tube placement. This study also noted an overall operator preference for the visual system over the conventional method (14). Sun et al. has studied the use of electromagnetic tracking system to identify the location of the NGT during the insertion process. With this technique, a permanent magnet is embedded within the tip of the NGT and a wearable device with embedded sensors is placed at the neck, which senses the passive magnetic field of the NGT as it traverses the esophagus into the stomach (15).

These navigational systems have yet to be adopted into standard clinical practice. However, in the future we may see increased adoption of these systems given the risk of aspiration, pneumonia, pneumothorax, hemothorax, esophageal perforation, or in some cases even death with incorrect placement of NGTs $(16,17)$.

Nasoenteric tube placement is a known risk factor for nosocomial sinusitis. These tubes can cause obstruction of the nasal ostia and provide a conduit for colonization of the nasopharynx by gastric microorganisms. One prospective epidemiologic study performed in ICU patients noted that feeding through a NGT was associated with increased risk of sinusitis (OR 14.1, $\mathrm{P}=0.015$ ) (18). A subsequent epidemiologic study also found that while there was an overall low incidence $(0.15 \%)$ of nosocomial sinusitis, the combination of nasoenteric and endotracheal intubation was associated with increased odds of sinusitis compared with endotracheal intubation alone (19).

Furthermore, prolonged use of NGTs can lead to nasal and esophageal ulcerations, aspiration pneumonia, and gastroesophageal reflux disease. These tubes can also cause trauma to the stomach, peptic esophagitis, stricture formation, and even tracheoesophageal fistula formation (20).

These complications are less of a concern with PEG tubes, which enter the stomach directly, bypassing the nasopharynx and esophagus. PEG tubes also have lower rates of intervention failure and offer patients an improved quality of life. As such they are preferred for longer term nutrition.

One systemic review evaluated rates of intervention failure (e.g., feeding interruption, blockage or leakage of the tube, treatment non-adherence) and concluded failure rates 
in the PEG tube population were significantly lower than failure rates in the NGT population at $9.22 \%$ and $39.11 \%$, respectively ( $\mathrm{RR} 0.18,95 \% \mathrm{CI}, 0.05-0.59, \mathrm{P}=0.005$ ). However, the review failed to demonstrate differences in mortality, complications of the intervention, aspiration rates, and nutritional status (21).

\section{Gastric vs. post-pyloric enteral feeding}

While PEG is often the preferred method of providing long term enteral nutrition, the concern with gastric feeding is the risk of aspiration, particularly in critically ill patients who may have delayed gastric emptying and altered mentation. Post-pyloric feeding may be preferred in patients with gastroparesis, gastric outlet obstruction, or history of gastrectomy. There are different methods to achieve post-pyloric feeding. The percutaneous endoscopic gastrojejunostomy (PEG-J) is commonly used and is achieved by advancing a smaller tube through a PEG tube with placement of the distal end of the smaller tube in the jejunum. An alternative approach is achieved through direct percutaneous endoscopic jejunostomy (PEJ), whereby a large bore feeding tube is directly placed in the jejunum under endoscopic guidance (22). PEG-J and PEJ tubes are more technically challenging to place and require specialized equipment and training, but may offer an advantage over PEG by minimizing aspiration risk.

One meta-analysis found that PEJ was able to reduce gastric residual volumes and was more likely to meet the energy requirements of a patient, but did not provide significant benefit over PEG tubes (23). Another study in trauma patients also found that patients who utilized PEG-J for post-pyloric feeding and gastric decompression were able to reach their goal rates faster than patients with PEG. However, there was no difference in ventilator days, pneumonia, sepsis, or hospital length of stay (24).

Several recent meta-analyses found evidence demonstrating lower rates of pneumonia with post-pyloric feeding compared with gastric feeding. Nonetheless, there was no difference in ventilator days or mortality between the two groups in these studies (25-27).

\section{Timing of feeds}

Some studies have suggested that early enteral nutrition reduces the risk of mortality in critically ill patients as compared with delayed initiation of enteral nutrition (28). Early enteral nutrition for stroke patients with dysphagia also showed improvement in mortality (29).

Current European Society for Clinical Nutrition and Metabolism (ESPEN) and American Society of Parenteral and Enteral Nutrition (ASPEN) guidelines recommend consideration of starting enteral nutrition after $24-48$ hours in the ICU. Enteral nutrition is recommended over parenteral nutrition when clinically appropriate $(30,31)$. However, the majority of mechanically ventilated patients who receive enteral nutrition do not receive sufficient caloric intake to meet their daily energy requirements (32).

While the use of enteral nutrition alone often does not meet the caloric needs, early initiation of parenteral nutrition to supplement enteral nutrition has not been proven to be beneficial. One randomized control trial demonstrated that delayed parenteral nutrition in these patients was associated with shorter ICU length of stay, shorter duration of mechanical ventilation, shorter hospital length of stay, and reduced hospital costs (33).

While early feeding is recommended in the critical care setting, there has been conflicting evidence regarding whether high calorie feeding or trophic feeding offers greater benefit. A recent study has illustrated the feasibility of early trophic feeding in patients with septic shock as a potential approach to improve enteric immune function during the hyper-acute phase of sepsis (34).

However, one randomized control trial evaluated patients with acute lung injury and found that initial trophic feeding for 6 days as compared with early full caloric feeding did not improve ventilator free days, 60-day mortality, or incidence of pneumonia, but did lower the risk of gastrointestinal complications (35). A subsequent study also demonstrated that permissive underfeeding was associated with no difference in feeding intolerance (e.g., vomiting, abdominal distention, or gastric residual over $200 \mathrm{cc}$ ), diarrhea, ICUassociated infections, or mortality when compared to full caloric feeding (36).

\section{Patient selection}

PEG is indicated for patients who require long-term nutritional support ( $>30$ days) and have a functional gastrointestinal tract, but without sufficient oral intake (37).

Neurologic dysphagia is one of the most common reasons for PEG tube insertion. Neurologic indications include stroke, dementia, amyotrophic lateral sclerosis (ALS), Guillain-Barré Syndrome, Parkinson's disease, cerebral palsy, multiple sclerosis (MS), myasthenia gravis, Huntington's disease, encephalitis, meningitis, and 
polymyositis (38).

PEG tube insertion is also common in patients with physical obstruction of the upper gastrointestinal tract as seen with head and neck cancers, esophageal cancers, or trauma. PEG tube placement can also be indicated for decompression, such as in gastric outlet obstruction.

\section{Cerebrovascular disease/stroke}

Dysphagia can occur in up to $65 \%$ of patients with stroke. George et al. found that $8.5 \%$ of patients hospitalized for stroke received tracheostomy in addition to PEG tube placement. Receiving a tracheostomy during an admission was the strongest predictor for subsequently receiving a PEG on that same admission (adjusted odds ratio 0.27 , 95\% CI, 0.24-0.29). Early PEG tube placement ( $<7$ days) during a hospitalization for stroke was associated with shorter length of stay, greater odds of discharge to home or acute rehabilitation, and lower odds of discharge to skilled nursing or long-term care (39).

Patients with higher stroke severity, worse dysphagia severity, diabetes, history of prior intracerebral hemorrhage, increased age, and health insurance coverage have a significantly increased likelihood of PEG placement (40).

\section{Motor neuron disease/ALS}

ALS is a rapidly progressive neurologic disease that leads to quadriplegia, dysarthria, and dysphagia. PEG placement in ALS has been shown to be safe even in patients with pulmonary dysfunction and may improve quality of life (41-43).

\section{Dementia}

In the advanced stages of dementia, patients often develop feeding issues that can arise from difficulty with physically feeding themselves, controlling a food bolus, and swallowing. They may have difficulty recognizing food and have malfunction with the limbic and hypothalamic systems that regulate hunger and satiety. PEG tube placement in patients with dementia is very common and the decision to place a PEG tube is often influenced by family member or caregiver concerns that the patient may starve. However, in patients with dementia, enteral feeding via PEG tube has not been shown to improve the risk of aspiration, pressure ulcers, pneumonia, or mortality as compared with oral feeding $(44,45)$. As such, the current American Geriatric
Society (AGS) guideline recommend oral feeding over PEG tube placement in patients with dementia (46).

Nevertheless, about one third of nursing home patients with dementia have PEG tubes (47). Hospital characteristics associated with higher rates of feeding tube placement include larger sized hospitals, for-profit hospitals, and hospitals with more ICU days documented for chronically ill patients within the last 6 months of life.

Black and Hispanic patients with dementia also have higher rates of PEG tube placement (48). It is unknown at this time if this is a result of cultural differences, disparities in health care access, or discrepancies in physician communication. Physician misperceptions regarding the utility of PEG tubes are also often a contributing factor to the overuse of PEG tubes in patients with dementia despite evidence to the contrary $(49,50)$.

\section{Head and neck malignancy}

Head and neck cancer is a common indication for PEG tube placement. Patients with head and neck cancers can experience difficulty swallowing for a variety of reasons including pain, obstruction by the tumor, or chemoradiation side effects including mucositis. In fact, dysphagia occurs in up to $54 \%$ of patients with advanced head and neck cancer treated with chemo-radiation (51).

One review showed that of all head and neck cancer patients studied, $30.5 \%$ had a gastrostomy tube placed at some time. Of all patients who receive treatment, 35.1\% had a gastrostomy tube placed. Of those who had tubes placed, $16.9 \%$ had their gastrostomy tubes placed before treatment and $83.1 \%$ were placed after treatment (52).

Given that many patients with head and neck cancer often have a long term need for enteral nutrition, some studies have evaluated the use of prophylactic PEG tube placement for patient with head and neck cancers and have found this practice to be safe and effective without increasing the risk of long term dysphagia (53).

Prophylactic PEG tube placement in patients with advanced head and neck cancer may also minimize weight loss during chemo-radiotherapy as compared with reactive PEG tube placement. Delayed PEG placement may be associated with increased risk of aspiration and stricture. However, timing of PEG tube placement does not improve tumor control or overall survival (54-56).

Alternatively, NGT remains a viable option to PEG tube placement in these patients. One recent study in patients with head and neck cancer found that while PEG provided 


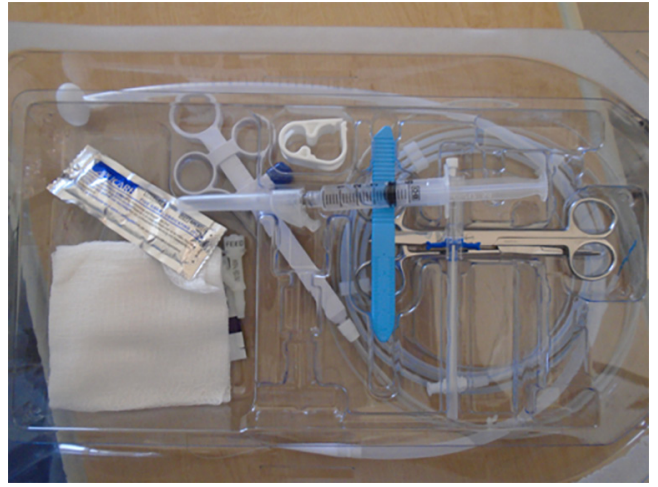

Figure 1 Boston Scientific EndoVive ${ }^{\mathrm{TM}} 20$ French Safety PEG kit, Pull technique.

better weight management, patients with NGT placement had the device in place for a significantly shorter period of time. The PEG tube was often considered by patients to be more cosmetically appealing and more convenient. There were no quality of life differences between the two study groups. NGT was associated with increased risk of dislodgement, but even accounting for this difference, PEG tubes were costlier $(57,58)$.

\section{Gastric decompression}

PEG tube placement for gastric decompression has also been described as a feasible palliative option for patients with malignant bowel obstruction, but is often associated with higher risk of complications and poor prognosis $(38,59,60)$.

\section{Miscellaneous}

PEG tube placement has been described in patients with Crohn's disease, cystic fibrosis, severe trauma, and altered level of consciousness (61).

\section{Procedure}

There are three main techniques for PEG tube placement: the per-oral push technique, the per-oral pull technique, and the direct percutaneous technique.

\section{Per-oral pull technique}

The most commonly used technique is the pull method as originally described by Gauderer et al. in 1980 (3). At our institution, we use the Boston Scientific EndoVive ${ }^{\mathrm{TM}} 20$ French Safety PEG kit (Figure 1) using the per-oral pull technique described below (Table 1).

The endoscope is passed into the stomach, which is then insufflated to achieve maximal apposition of the gastric and abdominal walls. A full esophagogastroduodenoscopy (EGD) is done to ensure that there is no obstruction or malignancy prior to PEG tube placement (Figure 2). This is critical to rule out any post-pyloric obstruction. Any abnormality should be documented. The gastrostomy site is located with a combination of trans-illumination and finger indentation of the abdominal wall (Figure $3 A, 3 B$ ). The ideal PEG tube location should be at the gastric antrum. Local anesthetic (lidocaine $1 \%$ with epinephrine) is infiltrated subcutaneously, and while maintaining a 90-degree angle with the abdominal wall, the local anesthetic is injected into the tract (Figure 3C).

A small skin incision is made to allow insertion of a needle-catheter combination also called trocar catheter (Figure $3 D-3 F$ ). The trocar catheter is then inserted along the designated tract into the stomach. There is a risk of colonic interposition between the gastric and abdominal walls during this procedure. As such, in addition to transillumination and finger indentation, direct visualization with aspiration of the needle syringe provides additional reassurance that there is no colonic interposition. If the needle is not directly visualized entering the stomach wall, but reflux of air is noted in the syringe, this may indicate inadvertent puncture of the transverse colon.

Once within the stomach, the needle is removed and the small wire loop at the end of the guidewire is passed through the catheter (Figure 3G). During this phase of the procedure, it is critical not to damage the posterior wall of the stomach during needle insertion. A snare system is passed through the endoscope and secures the wire loop (Figure $3 H$ ). The wire loop is then pulled up through the esophagus and out of the mouth (Figure 4A).

In the Ponsky technique (per-oral pull), the wire exiting the mouth is attached to the feeding tube. The wire and the feeding tube are then pulled down through the esophagus, into the stomach, and out through the anterior abdominal wall. It is important to lubricate the tube for smooth placement (Figure 4B). A skin disc (external bolster) is then placed over the feeding tube (Figure $5 A$ ). While visualizing the internal bumper with the endoscope, the external bolster is adjusted until the internal bumper is flush against the anterior stomach wall.

The external bolster is kept between $2-5 \mathrm{~cm}$ as indicated 
Table 1 The Per-oral pull technique for percutaneous endoscopic gastrostomy tube placement

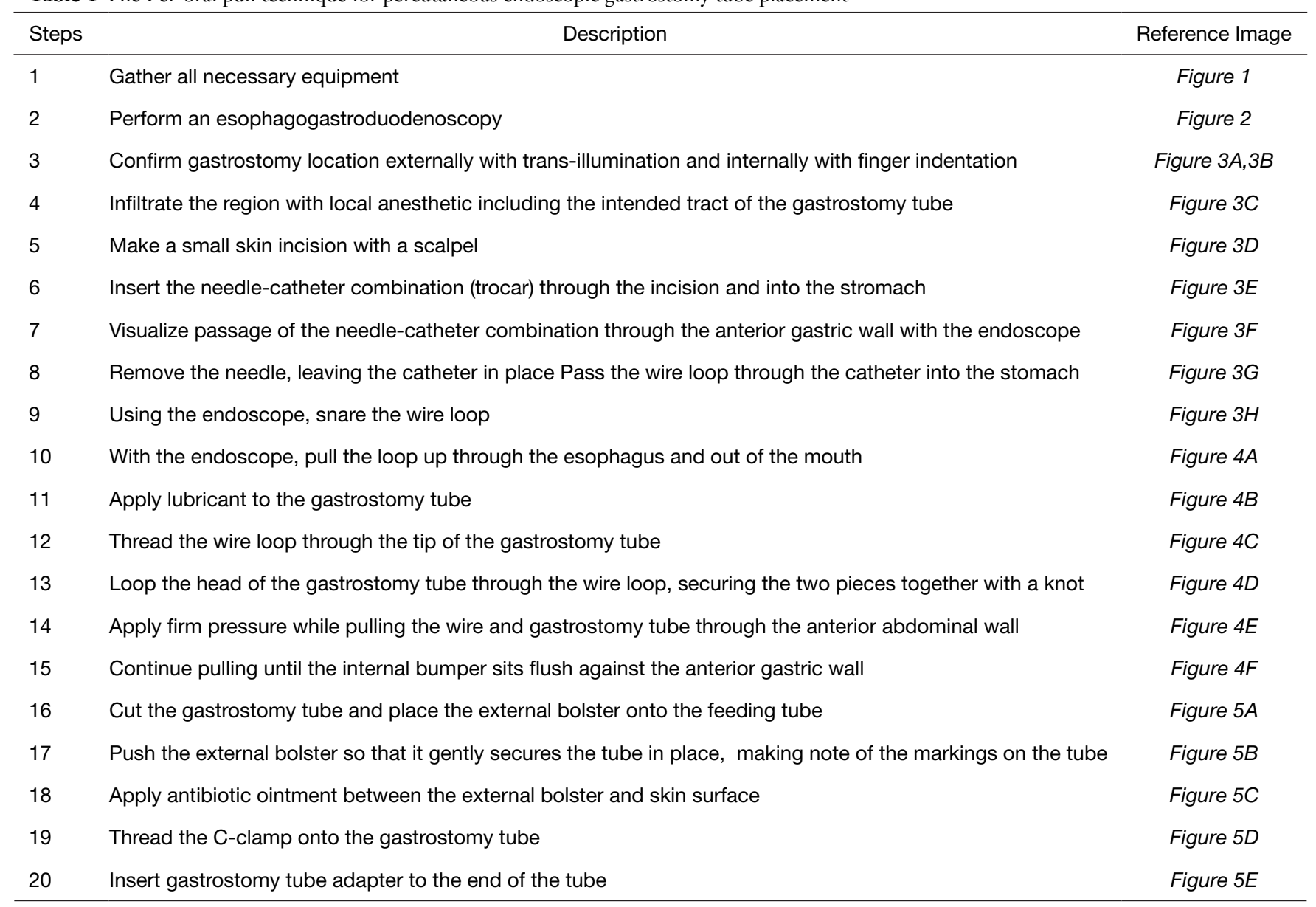

by the markings on the tube. This may vary depending on the patient's body habitus. Care should be made to ensure that the bolster is neither too tight nor too loose to prevent buried bumper syndrome or leakage, respectively (Figure $5 B$ ). Antibiotic ointment is applied between the bumper and the skin (Figure 5C). A clamp and an external port are added to the PEG tube to complete the procedure (Figure $5 D-5 F$ ). The external bolster should be evaluated the day after the procedure to ensure appropriate positioning. If the bolster is too tight, it may need adjustment or loosening.

\section{Per-oral push technique}

In the Sacks-Vine technique (per-oral push), the feeding tube is passed over the wire and pushed down through the stomach until the tapered end emerges through the skin. The guide wire is then withdrawn and the endoscope is reinserted to ensure proper positioning of the feeding tube.
A skin disc is secured over the feeding tube to keep it in place $(61,62)$.

The per-oral pull and per-oral push techniques, however, may not be possible or may be contraindicated in a variety of clinical scenarios. For example, patients with head and neck or esophageal cancer may have high-grade stenosis preventing the passage of the endoscope or the internal PEG tube bumper. Additionally, in patients with head and neck cancer, the passage of the tube through a primary site of malignancy may result in the implantation of cancer cells to the gastrostomy tube site resulting in abdominal wall metastasis (63).

\section{Introducer PEG technique}

For these patients, the Introducer PEG technique is an alternative to overcome the limitations of the traditional per-oral pull or push techniques (63). In the introducer 

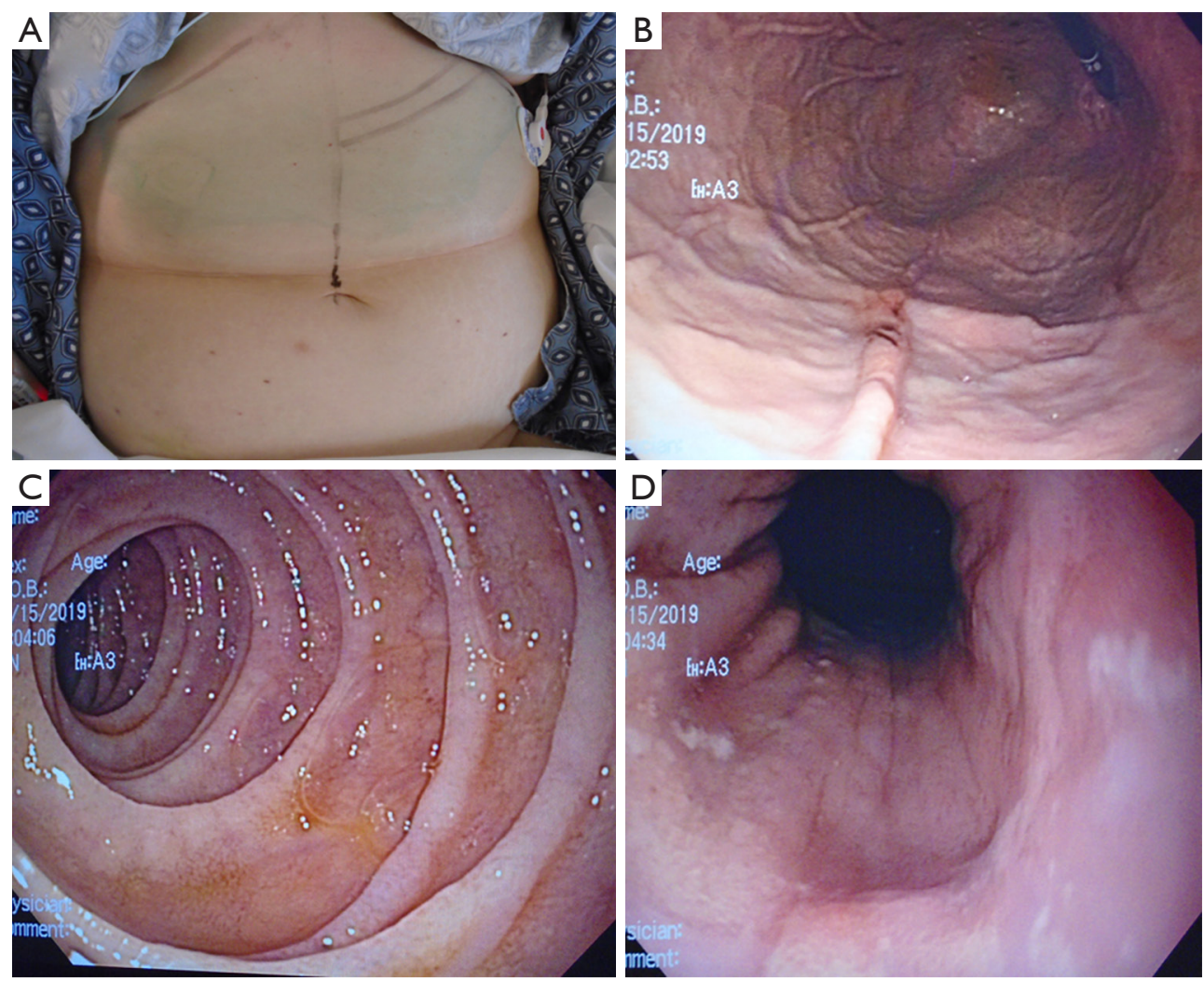

Figure 2 Pre-procedural evaluation for PEG tube placement. (A) Patient's abdomen marked with a surgical pen prior to the procedure; (B) endoscope retroflexed, evaluating the gastric cardia for lesions; (C) evaluating the duodenum for evidence of post-pyloric obstruction; (D) evaluating the esophagus for lesions.

PEG method, once the site of the gastrostomy is identified by trans-illumination and finger indentation, two to four sutures are placed under endoscopic guidance resulting in a gastropexy of the anterior gastric wall to the ventral abdominal wall. An incision is made between the sutures and a trocar with a peel-away sheath is introduced through the abdominal wall into the stomach. Alternatively, a guidewire can be introduced using the Seldinger technique with progressive dilation of the gastrostomy. The peelaway sheath is then introduced following dilation. A feeding tube is advanced through the sheath, which is then peeled off. An inflatable balloon at the tip of the feeding tube is filled with saline and serves as the internal bumper. A skin disc secures the tube externally. The gastropexy sutures are then removed. This technique can be used in patients with high-grade stenosis in the oropharynx or along the esophagus since it allows for use of an ultra-thin endoscope. Additionally, given that gastropexy is first achieved, this technique has been safely used in patients with ascites.
Another potential advantage of the introducer technique is that it avoids passage of the feeding tube through the oropharynx, thus preventing translocation of bacteria to the peristomal site. Several studies have suggested that there is a lower rate of peristomal skin infection associated with the introducer technique as compared with the peroral pull technique for PEG tube placement $(64,65)$. One randomized control trial has even suggested that with the introducer method, prophylactic antibiotics may no longer be needed (66).

\section{Percutaneous ultrasound gastrostomy (PUG) technique}

PUG is an alternative to the standard PEG techniques. It utilizes magnetic coaptation and ultrasound guidance instead of endoscopic guidance. The Point-of-care Ultrasound Magnet-Aligned Gastrostomy (PUMA-G) by CoapTech ${ }^{\mathrm{TM}}$ is the first system that has been approved by the US Food and Drug Administration (FDA) for this 

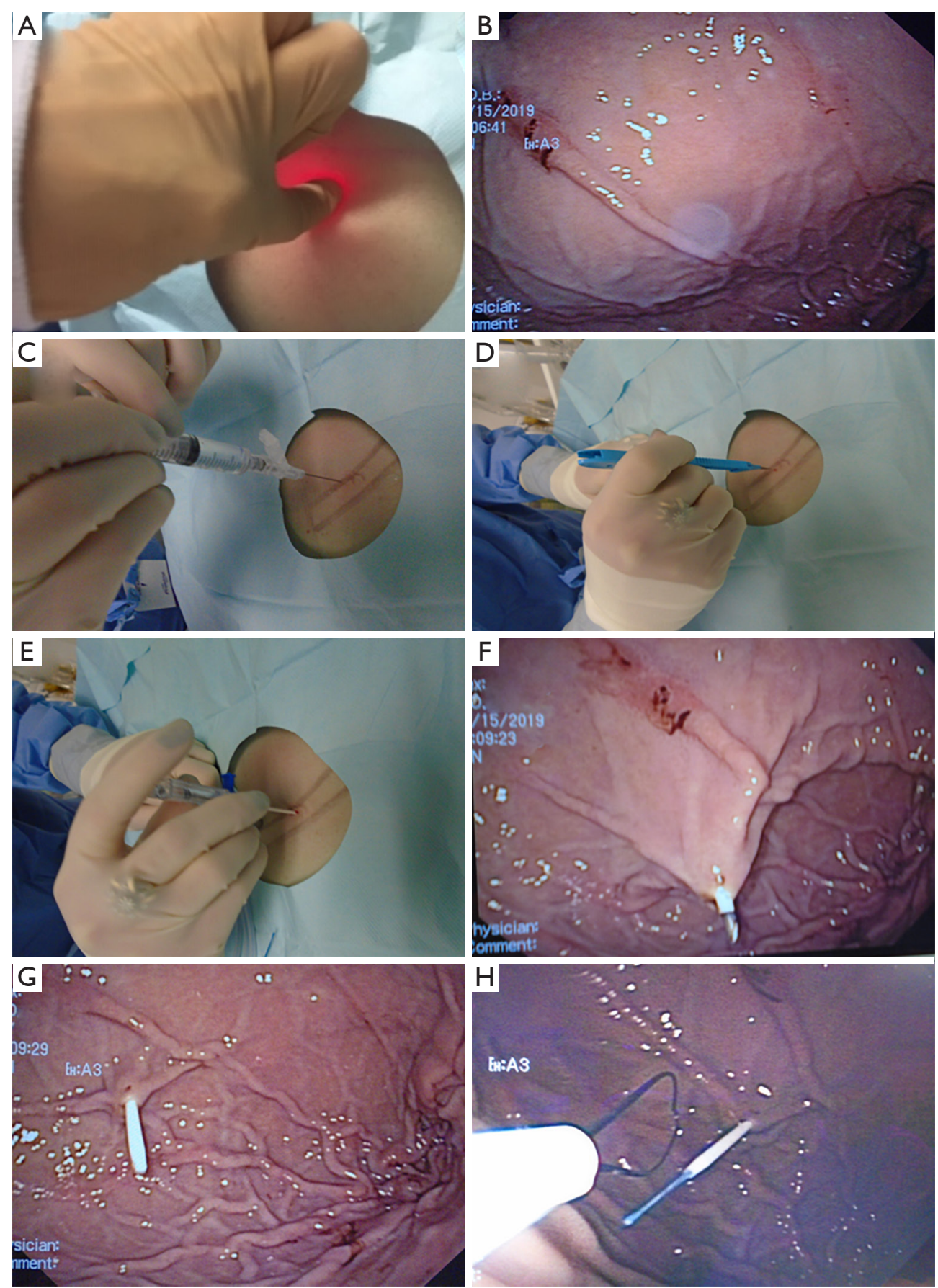

Figure 3 Insertion of the guidewire into the stomach. (A) Finger indentation at the site of trans-illumination; (B) indentation visualized from inside the stomach; (C) lidocaine with epinephrine administered at 90-degree angle to the surgical site; (D) small skin incision made with a scalpel at 90-degree angle; (E) insertion of the needle-catheter combination (trocar) through the incision at 90-degree angle; (F) visualization of the trocar from inside the stomach; $(\mathrm{G})$ catheter positioned inside the stomach with the needle withdrawn; $(\mathrm{H})$ snare system is passed through the endoscope and catches the wire loop. 

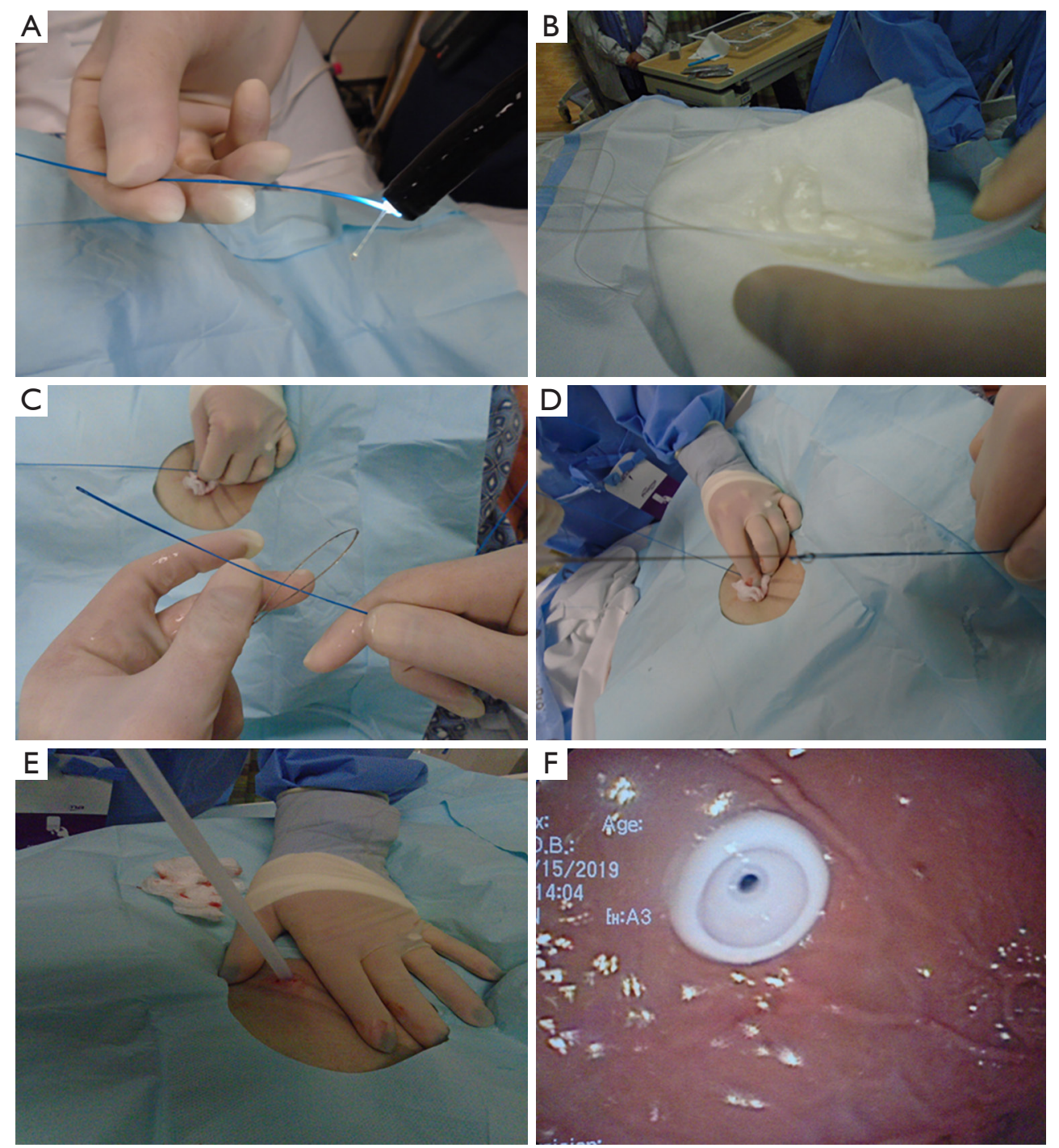

Figure 4 Placement of the PEG tube via the pull method. (A) Guidewire with wire loop pulled out of the mouth; (B) lubricating gel applied to the PEG tube prior to insertion; (C) PEG tube looped through the guidewire; (D) PEG tube attached to the guidewire via a knot; (E) firm pressure applied while pulling the PEG tube through the abdominal wall; (F) direct visualization of the PEG tube bumper from inside the stomach. PEG, percutaneous endoscopic gastrostomy.

technique (67).

In this technique, an existing orogastric or NGT in the stomach is used for insufflation. Then a specialized orogastric tube with a distal balloon, housing a bar magnet, is passed from the mouth into the stomach. A wire stylet is placed inside the tube to assist in the placement of the gastric tube balloon (GTB) within the stomach (Figure 6). Once the GTB is placed within the stomach, the wire stylet is removed and an external handheld magnet (EHM) is then placed over the GTB and used to move the GTB. The magnetic force between the internal bar magnet and the EHM bring the gastric wall and abdominal wall together to achieve a magnetic gastropexy. The GTB is then filled with saline via a Luer lock at the proximal end of the gastric tube. A handheld ultrasound is used to localize the saline filled GTB. Next, an introducer needle is inserted under direct ultrasound guidance into the saline-filled GTB. Subsequently, a guidewire with a coiled tip is inserted through the needle. Upon exiting the needle, the guidewire expands into its coiled configuration. The GTB is deflated 

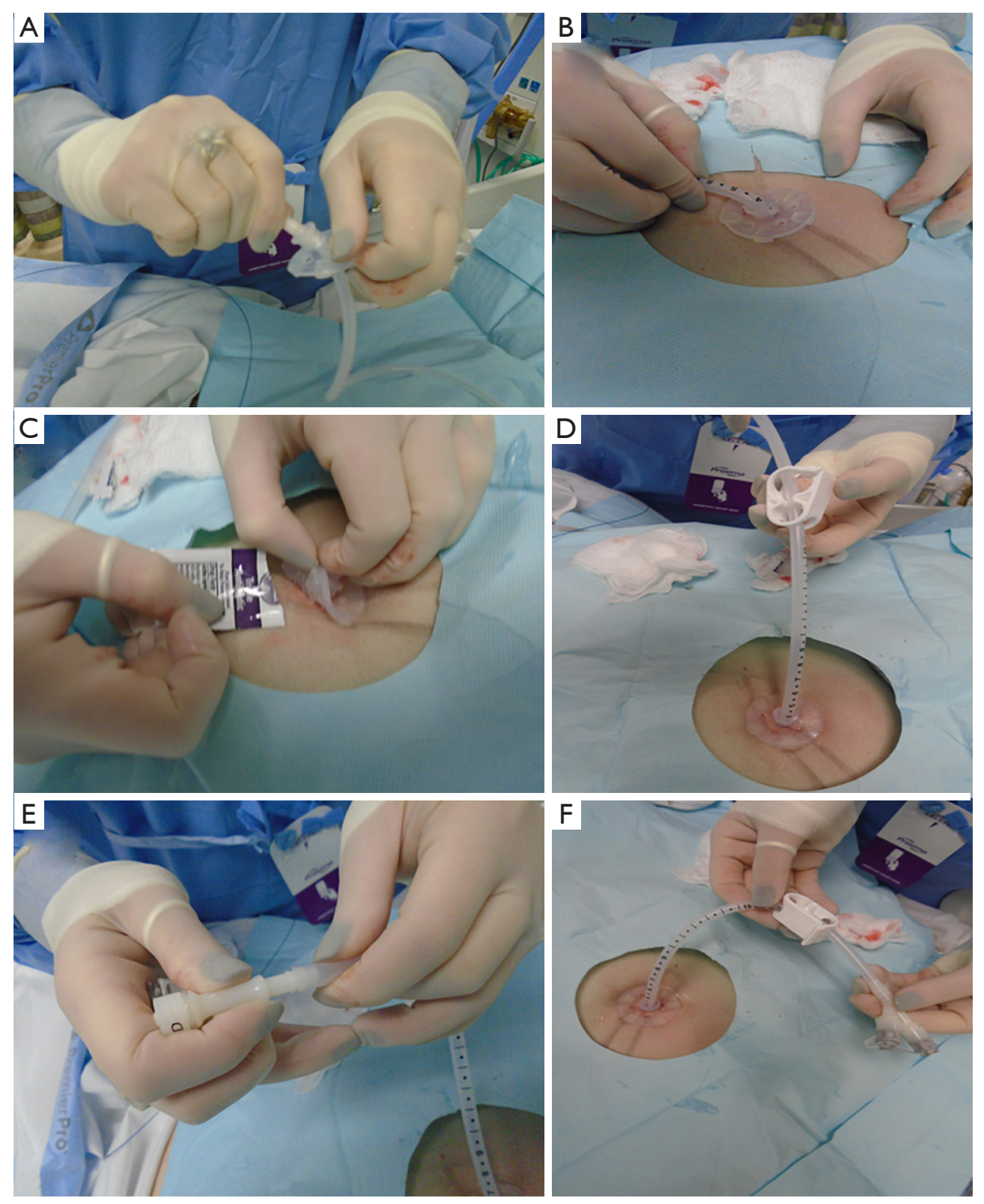

Figure 5 Completion of the PEG tube procedure. (A) External bolster placed onto the PEG tube; (B) skin marking on the external bolster kept at 2-5 cm depending on the patient's body habitus, making sure that the bolster is neither too tight nor too loose; (C) application of antibiotic ointment at the surgical site; (D) clamp positioned onto the PEG tube; (E) external port attached to the PEG tube; (F) successful placement of the PEG tube. PEG, percutaneous endoscopic gastrostomy.

to capture the coiled end of the guidewire within the balloon. The GTB catheter and guidewire is then pulled out of the mouth and a gastrostomy tube is fed over the guidewire in similar fashion as the Sacks-Vine per-oral push technique.

The safety and efficacy of the PUMA-G technique has been demonstrated in case series of five patients. All patients had their gastrostomy tubes placed successfully, and none had complications in the 30 days following tube placement. In this early experience, the average time for gastrostomy tube placement with the PUMA-G technique compared with standard PEG tube placement techniques was longer. Additionally, fluoroscopy was required to localize the GTB within the stomach and to guide EHM placement 


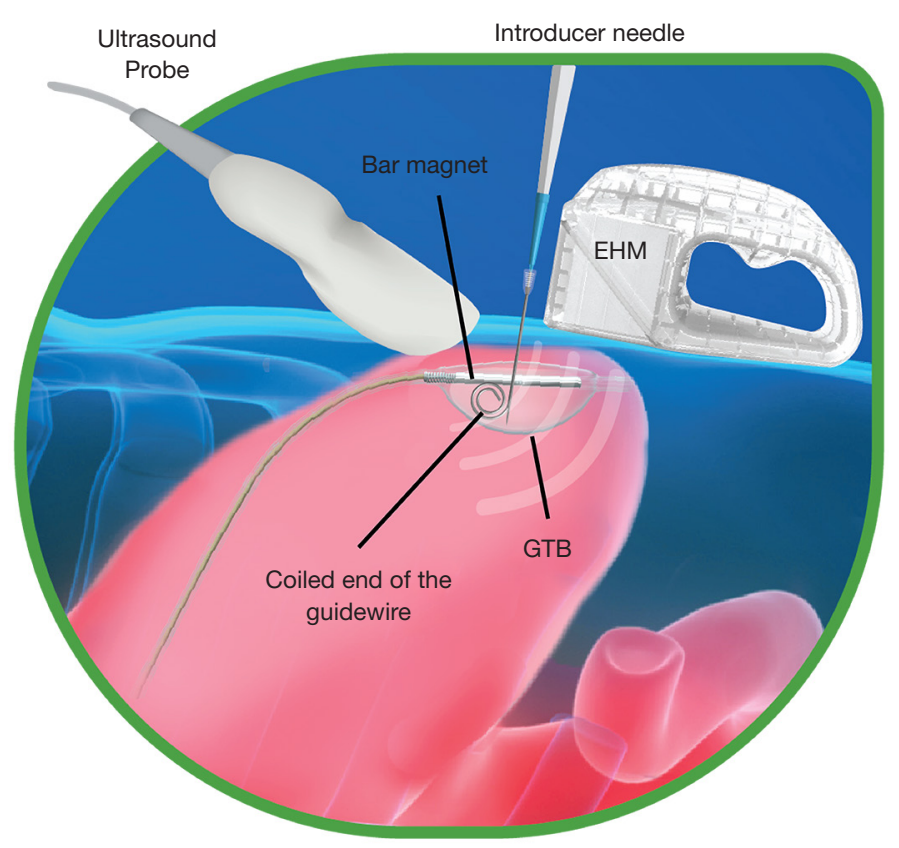

Figure 6 Illustration of the percutaneous ultrasound gastrostomy technique.

in 2 out of 5 patients, suggesting a learning curve for the operator (68). A second study (published in abstract form) also showed efficacy of the PUG with magnetic gastropexy technique, demonstrating success in 15 of 20 patients. In these patients that were evaluated, fluoroscopy was used to facilitate gastrostomy placement $95 \%$ of the time (69). However, both studies postulated that with continued operator experience PUG is feasible without fluoroscopy.

PUMA-G offers the advantage over traditional PEG tube techniques in that it can be done at the bedside with an ultrasound. The per-oral pull, per-oral push, and introducer techniques for PEG tube placement require specialized medical personnel and costly equipment. These may not be available in under-resourced settings and can be more expensive. However, further studies are needed to explore the safety and efficacy of the PUMA-G technique in comparison to standard PEG techniques. Another limitation of the PUMA-G system is that the EHM has only been FDA approved for gastropexy in patients with abdominal wall thickness $\leq 4.5 \mathrm{~cm}$ and maximal body mass index (BMI) between $30-35 \mathrm{~kg} / \mathrm{m}^{2}(67,68)$.

\section{Prophylactic use of antibiotics}

Patients who are candidates for PEG placement are often also at high risk of infection given malnutrition, immunosuppression, and underlying medical comorbidities. As such, current guidelines recommend use of prophylactic antibiotics prior to PEG placement to minimize the risk of peristomal infection. In patients not allergic to penicillin (PCN), a cephalosporin or PCN antibiotic should be administered 30 minutes before the procedure. Patients should also be screened for methicillin-resistant Staphylococcus aureus (MRSA). Patients who test positive for MRSA should undergo decontamination and receive prophylactic vancomycin (70).

\section{Contraindications}

Contraindications to PEG tube placement include severe coagulopathy, colonic interposition, history of subtotal or total gastrectomy, hemodynamic instability, sepsis, severe ascites, peritonitis, abdominal wall infection at the insertion site, peritoneal carcinomatosis, gastric outlet obstruction, and history of gastric varices (71).

\section{Obesity}

Obesity, as defined by BMI $>30 \mathrm{~kg} / \mathrm{m}^{2}$, can make transillumination more challenging and additional pressure is required on the abdominal wall to obtain successful trans-illumination. However, obesity is not a strict 
contraindication to PEG tube placement. PEG tube placement in overweight and obese patients can be done without increased risk of complications compared to patients with normal BMI $\left(18-25 \mathrm{~kg} / \mathrm{m}^{2}\right)$ as long as there is good trans-illumination and indentation, and colonic interposition is not suspected $(72,73)$.

Mackenzie et al. evaluated placement of direct percutaneous endoscopic jejunostomy (DPEJ) in obese and overweight patients (BMI $>25 \mathrm{~kg} / \mathrm{m}^{2}$ ) and found decreased success with a trend towards increased complications as compared to patients with normal BMI (74). Safe and successful PEG tube placement has been documented in a case series of super-morbidly obese patients $\left(\mathrm{BMI}>60 \mathrm{~kg} / \mathrm{m}^{2}\right)(75)$.

\section{Pregnancy}

PEG tubes are generally not used in pregnancy. This is due to the concern for uterine or fetal damage, the alteration of the intra-abdominal anatomy by the enlarging uterus, and the risk of infection. Nevertheless, there have been several case reports of successful PEG tube placement in pregnant patients with severe refractory hyperemesis gravidarum or who were comatose following trauma (76-79).

\section{Ascites}

Ascites is a relative contraindication for PEG tube placement, as it poses technical challenges for the procedure itself and increases risk of complications following the procedure. Ascitic fluid can make puncturing the anterior wall of the stomach more challenging. Ascites increases the intraperitoneal distance and can predispose to PEG tube dislodgement. Furthermore, ascitic fluid may prevent the maturation of a PEG tube tract thereby increasing risk of gastric fluid leakage and peritonitis.

However, Galaski et al. showed that in cases of malignant bowel obstruction, a palliative PEG tube for decompression can be performed successfully. These patients first had their ascites drained via placement of an intraperitoneal catheter, which was then followed by placement of a PEG tube. While these patients have a higher risk of complications, PEG tube placement is a feasible procedure $(80,81)$. Furthermore, the use of gastropexy can be used to prevent ascitic leakage around the PEG tube $(82,83)$.

\section{Initiation of tube feeding after PEG placement}

Enteral feeding is generally initiated $12-24$ hours after PEG tube placement. Despite its popularity, this practice is not based on evidence from randomized controlled trials. Kirby et al. in 1986 published one of the earliest studies that documented the efficacy and safety of same day feeding (84). Early feeding following PEG tube placement has been demonstrated to be safe by a number of subsequent prospective studies (85-88). Early tube feeding allows for earlier achievement of goal nutritional rates, potentially reducing healthcare costs by shortening inpatient hospitalization.

One meta-analysis by Bechtold et al., demonstrated that early ( $<4$ hour) feeding is safe and well tolerated when compared to delayed or next day feeding following PEG tube placement (89). A more recent meta-analysis by Szary et al., also showed that early ( $<3$ hours) feeding is safe when compared to delayed feeding (90).

\section{Complications}

\section{Acute complications}

Patients who undergo PEG tube placement are at risk for procedural complications. While the risk is relatively low $(0.1 \%)$, the procedure can be associated with significant morbidity and mortality. Possible complications from an endoscopy-guided procedure include aspiration, hemorrhage, and perforation. Sedation carries the risk of aspiration, hypotension, and hypoxia (12).

\section{Bleeding}

The post PEG-procedure bleeding risk is $2-2.5 \%$. The current American Society for Gastrointestinal Endoscopy (ASGE) guidelines state that aspirin and low dose nonsteroidal anti-inflammatory drugs (NSAIDs) can be continued in patients at high-risk for thromboembolic disease. In patients with low thromboembolic risk, the decision to hold aspirin or NSAIDs is left to the discretion of the operator. In patients with low thromboembolic risk, thienopyridines (e.g., clopidogrel) should be held for 7-10 days prior to the procedure. In patients with high thromboembolic risk, PEG tube placement should be delayed until the thienopyridine can be safely held. However, some studies have suggested that clopidogrel can 
be safely continued for PEG tube placement $(91,92)$.

Interestingly, Richter et al. found that while the use of aspirin or clopidogrel was not associated with increased risk of bleeding, serotonin reuptake inhibitors have been linked to increased risk of bleeding (93).

Warfarin should be held for 4-7 days prior to the procedure. Warfarin should be bridged if patients are at higher risk for thromboembolism such as those with valvular atrial fibrillation, mechanical heart valves, left ventricular assist devices, or recent diagnosis of thromboembolism.

Bleeding can usually be controlled with pressure over the abdominal wound. In the case of delayed external bleeding at the incision site, we use topical tranexamic acid $(5 \mathrm{~mL})$ and oxidized regenerated cellulose (Surgicel ${ }^{\mathrm{TM}}$ ). If there is any concern for internal bleeding, endoscopic or surgical exploration of bleeding source may be required, and the use of endoscopic clips may be needed for hemostasis (38).

\section{Peristomal wound infection}

Peristomal wound infection is the most common complication of PEG tube placement with an incidence ranging from $4-30 \%$ (87). Three quarters of these infections are minor and resolve with antibiotic treatment (94). Several randomized control studies have shown that antibiotic prophylaxis reduces the risk of peristomal wound infection compared to placebo (95-97).

This has been confirmed by a meta-analysis, which showed that the use of prophylactic antibiotics prior to PEG placement was associated with a $64 \%$ relative risk reduction and a $15 \%$ absolute risk reduction in peristomal wound infections. The number needed to treat to prevent one wound infection was eight (98). One study showed that nasopharyngeal decolonization of MRSA significantly reduced peristomal infection rates among patient colonized by MRSA (99).

Recent double blind, randomized control studies evaluating the modified introducer technique have suggested that prophylactic antibiotics may not be needed in the modified introducer technique. This technique, as described earlier, does not require passage of the feeding tube through the mouth thus minimizing translocation of the oral flora to the stoma site, which occurs with the peroral push and per-oral pull techniques $(66,100)$.

\section{Clogged feeding tube}

The incidence of clogged feeding tube has been reported as high as $23-35 \%$. Risk factors for clogging include use of thick enteral feeding formulas, use of bulking agents, and use of smaller bore feeding tube (8-9 Fr). For this reason, we use a $20 \mathrm{Fr}$ feeding tube at our institution for most cases.

One study showed that with increased acidity, particularly with $\mathrm{pH}<5.0$, proteins become less soluble, increasing the risk of gastrostomy tube clogging (101). Prophylactic use of pancreatic enzymes with sodium bicarbonate mixture has shown to be effective in maintaining tube patency $(102,103)$.

\section{Buried bumper syndrome (BBS)}

BBS is a severe complication of PEG tube placement which occurs when the internal bumper migrates along the stomal tract and is displaced outside of the gastric wall. This often occurs as a result of excessive compression between the internal bumper and external bolster. The incidence of BBS has been noted to be around 1\% (0.3-2.4\%). BBS can lead to gastrointestinal bleeding, perforation, peritonitis, or intra-abdominal abscess or phlegmon.

Patient specific risk factors for developing BBS include old age, immunosuppression, malnutrition, and treatment with steroids or chemotherapy. Internal bumper characteristics, PEG tube characteristics, and the quality of long term gastrostomy site care can affect the risk of developing BBS. Internal bumpers made of rigid or semirigid material or those with small contact area, sharp edges, or conical shape are at risk for developing BBS. Tubing with jejunal extension can cause the tubing to be positioned tangentially rather than perpendicularly, which also increases risk for developing BBS. It is recommended that as a preventative measure, the external bolster should be positioned about $10 \mathrm{~mm}$ away from the skin. Permanent dressing between the external bolster and the skin or excessive tightening of the external bolster can increase the risk for BBS. The timing of relaxing the external bolster positioning to $10 \mathrm{~mm}$ is controversial. Some operators prefer a tighter positioning of the external bolster in the first four days after PEG tube placement to prevent leakage at the stoma (104).

\section{Tumor tract seeding}

There is also a small but definite risk of tumor metastasis following PEG tube placement in patients with untreated head and neck cancers. One retrospective review of 304 patients with active head and neck cancer who underwent PEG placement noted a risk of $0.92 \%$ of developing 
abdominal wall metastasis (105). It has been suggested that the risk of tumor metastasis from head and neck cancer may be minimized with the use of the introducer technique for PEG placement (106).

\section{Inadvertent tube removal}

The rate of early PEG tube dislodgement has been reported as $0.6-4.0 \%$. When followed longitudinally for the lifetime of a new PEG, PEG tube dislodgement rates were observed to be $12.8 \%$. Dislodgement within 7 days of PEG tube placement, before the gastro-cutaneous tract has a chance to mature, results in an open gastrostomy. This allows for leakage of gastric contents and tube feeds into the intraperitoneal space, resulting in significant morbidity (107).

In patients who are disoriented or combative and at high risk of early tube dislodgement, various techniques have been described to minimize the risk of dislodgement, including endoscopic sutures, T-fasteners, and novel bumper designs (108-111).

\section{Peristomal leakage/irritation}

The reported incidence of peristomal leakage is around $1-2 \%$, but the actual incidence is likely much higher. Risk factors for peristomal leakage include delayed wound healing, infection, gastric hypersecretion, excessive cleaning with hydrogen peroxide, BBS, and torsion or instability of the PEG tube. Patients should be optimized from a nutrition and glycemic control standpoint preceding the PEG procedure.

Skin protectants and barrier creams such as zinc oxide should be applied. Excessive torsion applied by the external bumper should be relieved. Proton pump inhibitors should be initiated to minimize gastric acid secretion.

It is not recommended to exchange the PEG tube to a larger bore tube as this would result in enlarging the gastrocutaneous fistula and potentially exacerbate the problem. One strategy is to remove the PEG tube and allow the fistula to close before placing a new PEG tube. However, this can only be done once the gastro-cutaneous fistula tract has fully matured. As a last resort, the PEG tube can be removed and another PEG tube can be placed at a different site $(112,113)$.

\section{Gastro-colocutaneous fistulas}

Gastro-colocutaneous fistula can arise from inadvertent puncture of overlying bowel or erosion over time into adjacent intestine $(112,114)$. Risk factors include insufficient gastric insufflation, inadequate transillumination, or presence of adhesions which may result in trapped intestines. Patients may present acutely with peritonitis, fasciitis, or intestinal obstruction. However, more commonly the presentation is insidious, with leakage of fecal contents through the peristomal site or with watery diarrhea resembling tube feed formula. If a fistula is suspected, the patient should have a contrast study to confirm the anatomy (115). The fistulous tract can be managed conservatively by removal of the PEG tube and allowing for spontaneous fistula closure. In patients with large fistulas or delayed wound healing, the fistula can be closed surgically or endoscopically $(116,117)$.

\section{Interventional pulmonologists}

Interventional pulmonologists have expertise with endoscopic and procedural interventions. They are comfortable placing tracheostomies, which often are required in patients who simultaneously require PEG tube placement $(118,119)$. Therefore, the next logical evolution would be for interventional pulmonologists to perform both procedures at the same time when indicated. This would minimize the risks associated with sedation and paralytics as the two procedures can be merged into a single coordinated procedure performed by the same physician.

One small retrospective study demonstrated that interventional pulmonologists were able to place PEG tubes at bedside with $97.2 \%$ success rate (70 of 72 patients). Forty-one of the 70 PEG tubes placed (58\%) were performed immediately after percutaneous tracheostomy. There were no complications associated with PEG tube placement. Mild cellulitis around the PEG tube site was noted in 1 patient (1.4\%). This study found a 30 -day mortality rate of $11.94 \%$ as compared with $25 \%$ in gastroenterology literature (120).

Another prospective study demonstrated similar efficacy and safety of PEG tube placement with bronchoscopic guidance in the ICU by interventional pulmonologists with a $97.6 \%$ success rate and $2.4 \%$ complication rate. Only minor complications including soft tissue infection and G-tube malfunction were noted. No major complications were noted. 30-day mortality in this study was $11.9 \%$ (121).

However, we prefer endoscopic rather than bronchoscopic assisted PEG placement since complete EGD is not possible with a bronchoscope. EGD is necessary 
to rule out post-pyloric obstruction. Additionally, adequate insufflation and trans-illumination with examination of the gastric cardia by retroflexion is not always possible with a bronchoscope.

\section{Conclusions}

Gastroenteric feeding plays an important role in the critically ill patient who is unable to take sufficient oral nutrition. PEG tube placement is an increasingly common procedure and frequently coincides with tracheostomy placement. Interventional pulmonologists already have expertise in percutaneous tracheostomy placement, and they can also place PEG tube safely and effectively. We believe that interventional pulmonary trainees should be educated in PEG techniques, allowing for simultaneous percutaneous tracheotomy and PEG tube placement.

\section{Acknowledgements}

Funding: None.

\section{Footnote}

Provenance and Peer Review: This article was commissioned by the Guest Editors (Jonathan S. Kurman, Ashutosh Sachdeva and Rahul Nanchal) for the series "Interventional Pulmonology in the Intensive Care Unit Environment" published in Fournal of Thoracic Disease. The article has undergone external peer review.

Conflicts of Interest: All authors have completed the ICMJE uniform disclosure form, available at: http://dx.doi. org/10.21037/jtd-19-3728. The series "Interventional Pulmonology in the Intensive Care Unit Environment" was commissioned by the editorial office without any funding sponsorship. The authors have no other conflicts of interest to declare.

Ethical Statement: The authors are accountable for all aspects of the work in ensuring that questions related to the accuracy or integrity of any part of the work are appropriately investigated and resolved.

Open Access Statement: This is an Open Access article distributed in accordance with the Creative Commons Attribution-NonCommercial-NoDerivs 4.0 International License (CC BY-NC-ND 4.0), which permits the non- commercial replication and distribution of the article with the strict proviso that no changes or edits are made and the original work is properly cited (including links to both the formal publication through the relevant DOI and the license). See: https://creativecommons.org/licenses/by-nc-nd/4.0/.

\section{References}

1. Sharma K, Mogensen KM, Robinson MK. Pathophysiology of Critical Illness and Role of Nutrition. Nutr Clin Pract 2019;34:12-22.

2. Mogensen KM, Robinson MK, Casey JD, et al. Nutritional Status and Mortality in the Critically Ill. Crit Care Med 2015;43:2605-15.

3. Gauderer MW, Ponsky JL, Izant RJ Jr. Gastrostomy without laparotomy: a percutaneous endoscopic technique 1980. Nutrition 1998;14:736-8.

4. Kalfarentzos F, Kehagias J, Mead N, et al. Enteral nutrition is superior to parenteral nutrition in severe acute pancreatitis: results of a randomized prospective trial. $\mathrm{Br} \mathrm{J}$ Surg 1997;84:1665-9.

5. Braunschweig CL, Levy P, Sheean PM, et al. Enteral compared with parenteral nutrition: a meta-analysis. Am J Clin Nutr 2001;74:534-42.

6. Heyland DK, Dhaliwal R, Drover JW, et al. Canadian Critical Care Clinical Practice Guidelines Committee. Canadian clinical practice guidelines for nutrition support in mechanically ventilated, critically ill adult patients. JPEN J Parenter Enteral Nutr 2003;27:355-73.

7. Gramlich L, Kichian K, Pinilla J, et al. Does enteral nutrition compared to parenteral nutrition result in better outcomes in critically ill adult patients? A systematic review of the literature. Nutrition 2004;20:843-8.

8. Chow R, Bruera E, Chiu L, et al. Enteral and parenteral nutrition in cancer patients: a systematic review and metaanalysis. Ann Palliat Med 2016;5:30-41.

9. Peter JV, Moran JL, Phillips-Hughes J. A meta-analysis of treatment outcomes of early enteral versus early parenteral nutrition in hospitalized patients. Crit Care Med 2005;33:213-20; discussion 260-1.

10. Harvey SE, Parrott F, Harrison DA, et al. Trial of the route of early nutritional support in critically ill adults. $\mathrm{N}$ Engl J Med 2014;371:1673-84.

11. Lewis SR, Schofield-Robinson OJ, Alderson P, et al. Enteral versus parenteral nutrition and enteral versus a combination of enteral and parenteral nutrition for adults in the intensive care unit. Cochrane Database Syst Rev 2018;6:CD012276. 
12. Itkin M, DeLegge MH, Fang JC, et al. Multidisciplinary practical guidelines for gastrointestinal access for enteral nutrition and decompression from the Society of Interventional Radiology and American Gastroenterological Association (AGA) Institute, with endorsement by Canadian Interventional Radiological Association (CIRA) and Cardiovascular and Interventional Radiological Society of Europe (CIRSE). Gastroenterology 2011;141:742-65.

13. Rivera R, Campana J, Hamilton C, et al. Small bowel feeding tube placement using an electromagnetic tube placement device: accuracy of tip location. JPEN J Parenter Enteral Nutr 2011;35:636-42.

14. Li Q, Xie J, Wu J, et al. Novel Visual Nasogastric Tube Insertion System: A Feasibility and Efficiency Study in a Manikin. Gastroenterol Res Pract 2016;2016:7532172.

15. Sun Z, Foong S, Maréchal L, et al. A Non-invasive Realtime Localization System for Enhanced Efficacy in Nasogastric Intubation. Ann Biomed Eng 2015;43:2941-52.

16. Rassias AJ, Ball PA, Corwin HL. A prospective study of tracheopulmonary complications associated with the placement of narrow-bore enteral feeding tubes. Crit Care 1998;2:25-8.

17. Metheny NA, Meert KL, Clouse RE. Complications related to feeding tube placement. Curr Opin Gastroenterol 2007;23:178-82.

18. George DL, Falk PS, Umberto Meduri G, et al. Nosocomial sinusitis in patients in the medical intensive care unit: a prospective epidemiological study. Clin Infect Dis 1998;27:463-70.

19. Metheny NA, Hinyard LJ, Mohammed KA. Incidence of Sinusitis Associated With Endotracheal and Nasogastric Tubes: NIS Database. Am J Crit Care 2018;27:24-31.

20. Cataldi-Betcher EL, Seltzer MH, Slocum BA, et al. Complications occurring during enteral nutrition support: a prospective study. JPEN J Parenter Enteral Nutr 1983;7:546-52.

21. Gomes CA Jr, Andriolo RB, Bennett C, et al. Percutaneous endoscopic gastrostomy versus nasogastric tube feeding for adults with swallowing disturbances. Cochrane Database Syst Rev 2015;2015:CD008096.

22. Fan AC, Baron TH, Rumalla A, et al. Comparison of direct percutaneous endoscopic jejunostomy and PEG with jejunal extension. Gastrointest Endosc 2002;56:890-4.

23. Zhang Z, Xu X, Ding J, et al. Comparison of postpyloric tube feeding and gastric tube feeding in intensive care unit patients: a meta-analysis. Nutr Clin Pract 2013;28:371-80.

24. Adams GF, Guest DP, Ciraulo DL, et al. Maximizing tolerance of enteral nutrition in severely injured trauma patients: a comparison of enteral feedings by means of percutaneous endoscopic gastrostomy versus percutaneous endoscopic gastrojejunostomy. J Trauma 2000;48:459-64; discussion 464-5.

25. Alkhawaja S, Martin C, Butler RJ, et al. Post-pyloric versus gastric tube feeding for preventing pneumonia and improving nutritional outcomes in critically ill adults. Cochrane Database Syst Rev 2015;2015:CD008875.

26. Alhazzani W, Almasoud A, Jaeschke R, et al. Small bowel feeding and risk of pneumonia in adult critically ill patients: a systematic review and meta-analysis of randomized trials. Crit Care 2013;17:R127.

27. Deane AM, Dhaliwal R, Day AG, et al. Comparisons between intragastric and small intestinal delivery of enteral nutrition in the critically ill: a systematic review and metaanalysis. Crit Care 2013;17:R125.

28. Doig GS, Heighes PT, Simpson F, et al. Early enteral nutrition, provided within $24 \mathrm{~h}$ of injury or intensive care unit admission, significantly reduces mortality in critically ill patients: a meta-analysis of randomised controlled trials. Intensive Care Med 2009;35:2018-27.

29. Dennis MS, Lewis SC, Warlow C, et al. Effect of timing and method of enteral tube feeding for dysphagic stroke patients (FOOD): a multicentre randomised controlled trial. Lancet 2005;365:764-72.

30. Singer P, Blaser AR, Berger MM, et al. ESPEN guideline on clinical nutrition in the intensive care unit. Clin Nutr 2019;38:48-79.

31. McClave SA, Taylor BE, Martindale RG, et al. Guidelines for the Provision and Assessment of Nutrition Support Therapy in the Adult Critically Ill Patient: Society of Critical Care Medicine (SCCM) and American Society for Parenteral and Enteral Nutrition (A.S.P.E.N.). JPEN J Parenter Enteral Nutr 2016;40:159-211.

32. O'Leary-Kelley CM, Puntillo KA, Barr J, et al. Nutritional adequacy in patients receiving mechanical ventilation who are fed enterally. Am J Crit Care 2005;14:222-31.

33. Casaer MP, Mesotten D, Hermans G, et al. Early versus late parenteral nutrition in critically ill adults. $\mathrm{N} \mathrm{Engl} \mathrm{J}$ Med 2011 Aug 11;365:506-17.

34. Patel JJ, Kozeniecki M, Peppard WJ, et al. Phase 3 Pilot Randomized Controlled Trial Comparing Early Trophic Enteral Nutrition With "No Enteral Nutrition" in Mechanically Ventilated Patients With Septic Shock. JPEN J Parenter Enteral Nutr 2020;44:866-73.

35. Rice TW, Wheeler AP, Thompson BT, et al. Initial trophic vs full enteral feeding in patients with acute lung injury: 
the EDEN randomized trial. JAMA 2012;307:795-803.

36. Arabi YM, Aldawood AS, Haddad SH, et al. Permissive Underfeeding or Standard Enteral Feeding in Critically Ill Adults. N Engl J Med 2015;372:2398-408.

37. Vujasinovic M, Ingre C, Baldaque Silva F, et al. Complications and outcome of percutaneous endoscopic gastrostomy in a high-volume centre. Scand J Gastroenterol 2019;54:513-8.

38. Rahnemai-Azar AA, Rahnemaiazar AA, Naghshizadian R, et al. Percutaneous endoscopic gastrostomy: indications, technique, complications and management. World J Gastroenterol 2014;20:7739-51.

39. George BP, Kelly AG, Albert GP, et al. Timing of Percutaneous Endoscopic Gastrostomy for Acute Ischemic Stroke: An Observational Study From the US Nationwide Inpatient Sample. Stroke 2017;48:420-7.

40. Brown K, Cai C, Barreto A, et al. Predictors of Percutaneous Endoscopic Gastrostomy Placement in Acute Ischemic Stroke. J Stroke Cerebrovasc Dis 2018;27:3200-7.

41. Mathus-Vliegen LM, Louwerse LS, Merkus MP, et al. Percutaneous endoscopic gastrostomy in patients with amyotrophic lateral sclerosis and impaired pulmonary function. Gastrointest Endosc 1994;40:463-9.

42. Kirstein MM, Körner S, Schneider A, et al. Percutaneous endoscopic gastrostomy with and without jejunal extension in patients with amyotrophic lateral sclerosis. Eur J Gastroenterol Hepatol 2018;30:257-62.

43. ProGas Study Group. Gastrostomy in patients with amyotrophic lateral sclerosis (ProGas): a prospective cohort study. Lancet Neurol 2015;14:702-9.

44. Murphy LM, Lipman TO. Percutaneous Endoscopic Gastrostomy Does Not Prolong Survival in Patients With Dementia. Arch Intern Med 2003;163:1351-3.

45. Sampson EL, Candy B, Jones L. Enteral tube feeding for older people with advanced dementia. Cochrane Database Syst Rev 2009;2009:CD007209.

46. American Geriatrics Society Ethics Committee and Clinical Practice and Models of Care Committee. American Geriatrics Society feeding tubes in advanced dementia position statement. J Am Geriatr Soc 2014;62:1590-3.

47. Mitchell SL, Teno JM, Roy J, et al. Clinical and organizational factors associated with feeding tube use among nursing home residents with advanced cognitive impairment. JAMA 2003;290:73-80.

48. Teno JM, Mitchell SL, Gozalo PL, et al. Hospital Characteristics Associated With Feeding Tube Placement in Nursing Home Residents With Advanced Cognitive Impairment. JAMA 2010;303:544-50.

49. Mohandas N, Kumar R, Leelakrishnan V, et al. International Survey of Physicians' Perspectives on Percutaneous Endoscopic Gastrostomy Tube Feeding in Patients with Dementia and Review of Literature. Cureus 2019;11:e4578.

50. Gieniusz M, Sinvani L, Kozikowski A, et al. Percutaneous Feeding Tubes in Individuals with Advanced Dementia: Are Physicians "Choosing Wisely"? J Am Geriatr Soc 2018;66:64-69.

51. Kraaijenga SA, Oskam IM, van der Molen L, et al. Evaluation of long term (10-years+) dysphagia and trismus in patients treated with concurrent chemoradiotherapy for advanced head and neck cancer. Oral Oncol 2015;51:787-94.

52. Locher JL, Bonner JA, Carroll WR, et al. Gastrostomy tube placement and use in patients with head and neck cancer. Head Neck 2012;34:422-8.

53. Axelsson L, Silander E, Nyman J, et al. Effect of prophylactic percutaneous endoscopic gastrostomy tube on swallowing in advanced head and neck cancer: A randomized controlled study. Head Neck 2017;39:908-15.

54. Wiggenraad RG, Flierman L, Goossens A, et al. Prophylactic gastrostomy placement and early tube feeding may limit loss of weight during chemoradiotherapy for advanced head and neck cancer, a preliminary study. Clin Otolaryngol 2007;32:384-90.

55. Brown TE, Banks MD, Hughes BGM, et al. Randomised controlled trial of early prophylactic feeding vs standard care in patients with head and neck cancer. Br J Cancer 2017;117:15-24.

56. McClelland S 3rd, Andrews JZ, Chaudhry H, et al. Prophylactic versus reactive gastrostomy tube placement in advanced head and neck cancer treated with definitive chemoradiotherapy: A systematic review. Oral Oncol 2018;87:77-81.

57. Corry J, Poon W, McPhee N, et al. Prospective study of percutaneous endoscopic gastrostomy tubes versus nasogastric tubes for enteral feeding in patients with head and neck cancer undergoing (chemo)radiation. Head Neck 2009;31:867-76.

58. Wang J, Liu M, Liu C, et al. Percutaneous endoscopic gastrostomy versus nasogastric tube feeding for patients with head and neck cancer: a systematic review. J Radiat Res 2014;55:559-67.

59. Cunningham MJ, Bromberg C, Kredentser DC, et al. Percutaneous gastrostomy for decompression in patients 
with advanced gynecologic malignancies. Gynecol Oncol 1995;59:273-6.

60. Pinard KA, Goring TN, Egan BC, et al. Drainage Percutaneous Endoscopic Gastrostomy for Malignant Bowel Obstruction in Gastrointestinal Cancers: Prognosis and Implications for Timing of Palliative Intervention. J Palliat Med 2017;20:774-8.

61. Belanger A, Akulian J. Interventional pulmonology in the intensive care unit: percutaneous tracheostomy and gastrostomy. Semin Respir Crit Care Med 2014;35:744-50.

62. Vudayagiri L, Gemma R. Percutaneous Endoscopic Gastrostomy (PEG) Tube. Treasure Island (FL): StatPearls Publishing, 2020.

63. Van Dyck E, Macken EJ, Roth B, et al. Safety of pulltype and introducer percutaneous endoscopic gastrostomy tubes in oncology patients: a retrospective analysis. BMC Gastroenterol 2011;11:23.

64. Maetani I, Tada T, Ukita T, et al. PEG with introducer or pull method: a prospective randomized comparison. Gastrointest Endosc 2003;57:837-41.

65. Campoli PM, de Paula AA, Alves LG, et al. Effect of the introducer technique compared with the pull technique on the peristomal infection rate in PEG: a meta-analysis. Gastrointest Endosc 2012;75:988-96.

66. Shastri YM, Hoepffner N, Tessmer A, et al. New introducer PEG gastropexy does not require prophylactic antibiotics: multicenter prospective randomized double-blind placebocontrolled study. Gastrointest Endosc 2008;67:620-8.

67. Wilkerson RG, Pustavoitau A, Carolan H, et al. Percutaneous ultrasound gastrostomy: a novel device and bedside procedure for gastrostomy tube insertion using magnetic and ultrasound guidance. J Med Dev 2019;13:024501.

68. Cool DW, Chung J, Wiseman D, et al. Percutaneous Ultrasound Gastrostomy: First-in-Human Experience with the PUMA-G System. J Vasc Interv Radiol 2020;31:808-11.

69. Dhiman N, Lichliter A, Rothenberg E, et al. 3:27 PM Abstract No. 221 Multicenter preliminary experience with percutaneous ultrasound gastrostomy: Do interventional radiologists need fluoroscopy for gastrostomy placement? J Vasc Interv Radiol 2020;31:S100.

70. Banerjee S, Shen B, Baron TH, et al. Antibiotic prophylaxis for GI endoscopy. Gastrointest Endosc 2008;67:791-8.

71. Hucl T, Spicak J. Complications of percutaneous endoscopic gastrostomy. Best Pract Res Clin Gastroenterol 2016;30:769-81.
72. McGarr SE, Kirby DF. Percutaneous endoscopic gastrostomy (PEG) placement in the overweight and obese patient. JPEN J Parenter Enteral Nutr 2007;31:212-6.

73. Wiggins TF, Garrow DA, DeLegge MH. Evaluation of percutaneous endoscopic feeding tube placement in obese patients. Nutr Clin Pract 2009;24:723-7.

74. Mackenzie SH, Haslem D, Hilden K, et al. Success rate of direct percutaneous endoscopic jejunostomy in patients who are obese. Gastrointest Endosc 2008;67:265-9.

75. Bochicchio GV, Guzzo JL, Scalea TM. Percutaneous endoscopic gastrostomy in the supermorbidly obese patient. JSLS 2006;10:409-13.

76. Koh ML, Lipkin EW. Nutrition support of a pregnant comatose patient via percutaneous endoscopic gastrostomy. JPEN J Parenter Enteral Nutr 1993;17:384-7.

77. Shaheen NJ, Crosby MA, Grimm IS, et al. The use of percutaneous endoscopic gastrostomy in pregnancy. Gastrointest Endosc 1997;46:564-5.

78. Irving PM, Howell RJ, Shidrawi RG. Percutaneous endoscopic gastrostomy with a jejunal port for severe hyperemesis gravidarum. Eur J Gastroenterol Hepatol 2004;16:937-9.

79. Senadhi V, Chaudhary J, Dutta S. Percutaneous endoscopic gastrostomy placement during pregnancy in the critical care setting. Endoscopy 2010;42 Suppl 2:E358-9.

80. Galaski A, Peng WW, Ellis M, et al. Gastrostomy tube placement by radiological versus endoscopic methods in an acute care setting: a retrospective review of frequency, indications, complications and outcomes. Can J Gastroenterol 2009;23:109-14.

81. Al-Abboodi Y, Ridha A, Fasullo M, et al. Risks of PEG tube placement in patients with cirrhosis-associated ascites. Clin Exp Gastroenterol 2017;10:211-4.

82. Wejda BU, Deppe H, Huchzermeyer H, et al. PEG placement in patients with ascites: a new approach. Gastrointest Endosc 2005;61:178-80.

83. Attam R, Arain MA, Leslie DB, et al. Endoscopic sutured gastropexy: a novel technique for performing a secure gastrostomy (with videos). Gastrointest Endosc 2014;79:1011-4.

84. Kirby DF, Craig RM, Tsang TK, et al. Percutaneous endoscopic gastrostomies: a prospective evaluation and review of the literature. JPEN J Parenter Enteral Nutr 1986;10:1559.

85. Choudhry U, Barde CJ, Markert R, et al. Percutaneous endoscopic gastrostomy: a randomized prospective comparison of early and delayed feeding. Gastrointest Endosc 1996;44:164-7. 
86. Stein J, Schulte-Bockholt A, Sabin M, et al. A randomized prospective trial of immediate vs. next-day feeding after percutaneous endoscopic gastrostomy in intensive care patients. Intensive Care Med 2002;28:1656-60.

87. Dubagunta S, Still CD, Kumar A, et al. Early initiation of enteral feeding after percutaneous endoscopic gastrostomy tube placement. Nutr Clin Pract 2002;17:123-5.

88. McCarter TL, Condon SC, Aguilar RC, et al. Randomized prospective trial of early versus delayed feeding after percutaneous endoscopic gastrostomy placement. Am J Gastroenterol 1998;93:419-21.

89. Bechtold ML, Matteson ML, Choudhary A, et al. Early versus delayed feeding after placement of a percutaneous endoscopic gastrostomy: a meta-analysis. Am J Gastroenterol 2008;103:2919-24.

90. Szary NM, Arif M, Matteson ML, et al. Enteral feeding within three hours after percutaneous endoscopic gastrostomy placement: a meta-analysis. J Clin Gastroenterol 2011;45:e34-8.

91. Anderson MA, Ben-Menachem T, Gan SI, et al. Management of antithrombotic agents for endoscopic procedures. Gastrointest Endosc 2009;70:1060-70.

92. Sohail U, Harleen C, Mahdi AO, et al. Bleeding risk with clopidogrel and percutaneous endoscopic gastrostomy. World J Gastrointest Endosc 2016;8:553-7.

93. Richter JA, Patrie JT, Richter RP, et al. Bleeding after percutaneous endoscopic gastrostomy is linked to serotonin reuptake inhibitors, not aspirin or clopidogrel. Gastrointest Endosc 2011;74:22-34.e1.

94. Blumenstein I, Shastri YM, Stein J. Gastroenteric tube feeding: techniques, problems and solutions. World J Gastroenterol 2014;20:8505-24.

95. Saadeddin A, Freshwater DA, Fisher NC, et al. Antibiotic prophylaxis for percutaneous endoscopic gastrostomy for non-malignant conditions: a double-blind prospective randomized controlled trial. Aliment Pharmacol Ther 2005;22:565-70.

96. Dormann AJ, Wigginghaus B, Risius H, et al. A single dose of ceftriaxone administered 30 minutes before percutaneous endoscopic gastrostomy significantly reduces local and systemic infective complications. Am J Gastroenterol 1999;94:3220-4.

97. Jain NK, Larson DE, Schroeder KW, et al. Antibiotic prophylaxis for percutaneous endoscopic gastrostomy. A prospective, randomized, double-blind clinical trial. Ann Intern Med 1987;107:824-8.

98. Jafri NS, Mahid SS, Minor KS, et al. Meta-analysis: antibiotic prophylaxis to prevent peristomal infection following percutaneous endoscopic gastrostomy. Aliment Pharmacol Ther 2007;25:647-56.

99. Horiuchi A, Nakayama Y, Kajiyama M, et al. Nasopharyngeal decolonization of methicillin-resistant Staphylococcus aureus can reduce PEG peristomal wound infection. Am J Gastroenterol 2006;101:274-7.

100.Adachi Y, Akino K, Mita H, et al. Systemic Prophylactic Antibiotics for the Modified Introducer Method for Percutaneous Endoscopic Gastrostomy: A Prospective, Randomized, Double-Blind Study. J Clin Gastroenterol 2016;50:727-32.

101.Marcuard SP, Perkins AM. Clogging of feeding tubes. JPEN J Parenter Enteral Nutr 1988;12:403-5.

102. Sriram K, Jayanthi V, Lakshmi RG, et al. Prophylactic locking of enteral feeding tubes with pancreatic enzymes. JPEN J Parenter Enteral Nutr 1997;21:353-6.

103. Bourgault AM, Heyland DK, Drover JW, et al. Prophylactic pancreatic enzymes to reduce feeding tube occlusions. Nutr Clin Pract 2003;18:398-401.

104. Cyrany J, Rejchrt S, Kopacova M, et al. Buried bumper syndrome: A complication of percutaneous endoscopic gastrostomy. World J Gastroenterol 2016;22:618-27.

105. Cruz I, Mamel JJ, Brady PG, et al. Incidence of abdominal wall metastasis complicating PEG tube placement in untreated head and neck cancer. Gastrointest Endosc 2005;62:708-53.

106.Huang AT, Georgolios A, Espino S, et al. Percutaneous endoscopic gastrostomy site metastasis from head and neck squamous cell carcinoma: case series and literature review. J Otolaryngol Head Neck Surg 2013;42:20.

107. Rosenberger LH, Newhook T, Schirmer B, et al. Late accidental dislodgement of a percutaneous endoscopic gastrostomy tube: an underestimated burden on patients and the health care system. Surg Endosc 2011;25:3307-11.

108. Timratana P, El-Hayek K, Shimizu H, et al. Percutaneous endoscopic gastrostomy (PEG) with T-fasteners obviates the need for emergent replacement after early tube dislodgement. Surg Endosc 2012;26:3541-7.

109. Rosenberger LH, Guidry CA, Davis JP, et al. Reducing Accidental Dislodgement of the Percutaneous Endoscopic Gastrostomy: A Prospective Trial of the "SafetyBreak" Device. Surg Innov 2016;23:62-9.

110.Agnihotri A, Barola S, Hill C, et al. Endoscopic suturing for the management of recurrent dislodgment of percutaneous endoscopic gastrostomy-jejunostomy tube. J Dig Dis 2018;19:170-6.

111. Shah R, Shah M. Gastrostomy Tube Replacement. Treasure Island (FL): StatPearls Publishing, 2019. 
112. McClave SA, Chang WK. Complications of enteral access. Gastrointest Endosc 2003;58:739-51.

113. Schrag SP, Sharma R, Jaik NP, et al. Complications related to percutaneous endoscopic gastrostomy (PEG) tubes. A comprehensive clinical review. J Gastrointestin Liver Dis 2007;16:407-18.

114.Berger SA, Zarling EJ. Colocutaneous fistula following migration of PEG tube. Gastrointest Endosc 1991;37:86-8.

115. Guloglu R, Taviloglu K, Alimoglu O. Colon injury following percutaneous endoscopic gastrostomy tube insertion. J Laparoendosc Adv Surg Tech A 2003;13:69-72.

116. Kim HS, Lee DK, Baik SK, et al. Endoscopic management of colocutaneous fistula after percutaneous endoscopic gastrostomy. Endoscopy 2002;34:430.

117. Gyökeres T, Burai M, Hamvas J, et al. Conservative vs. endoscopic closure of colocutaneous fistulas after

Cite this article as: Wei M, Ho E, Hegde P. An overview of percutaneous endoscopic gastrostomy tube placement in the intensive care unit. J Thorac Dis 2021;13(8):5277-5296. doi: $10.21037 /$ jtd-19-3728 percutaneous endoscopic gastrostomy complications. Endoscopy 2003;35:246-7; author reply 248.

118. Bhatti N, Mirski M, Tatlipinar A, et al. Reduction of complication rate in percutaneous dilation tracheostomies. Laryngoscope 2007;117:172-5.

119. Yarmus L, Pandian V, Gilbert C, et al. Safety and efficiency of interventional pulmonologists performing percutaneous tracheostomy. Respiration 2012;84:123-7.

120. Yarmus L, Gilbert C, Lechtzin N, et al. Safety and feasibility of interventional pulmonologists performing bedside percutaneous endoscopic gastrostomy tube placement. Chest 2013;144:436-40.

121. Folch E, Kheir F, Mahajan A, et al. Bronchoscope-Guided Percutaneous Endoscopic Gastrostomy Tube Placement by Interventional Pulmonologists: A Feasibility and Safety Study. J Intensive Care Med 2020;35:851-7. 